\title{
LASER PROCESSING
}

The laser process

claims certain

inherent advantages

pattern of alternating bright and dark regions on the crystal surface. The high-intensity light, by increasing electrochemical activity, produces the faster etching rate that defines the brighter regions. It is the difference in etch rates that yields a series of parallel grooves of alternating depths.

Meanwhile, George J. Collins, professor of electrical engineering at Colorado State University in Fort Collins, is enthusiastic about his results in depositing thin-film insulating materials. Collins and his group are using laser light to achieve photodissociation of gases and their subsequent depositions as insulators. Thus, silicon dioxide may be formed from the laser-induced photodissociation of nitrous oxide and ane. Having produced highly adhesive and uniform films that exhibit low-defect density, high breakdown voltage, and conformal step coverage, Collins is satisfied that the laserdeposited films are comparable with those produced by plasma depositon.

But the laser process in addition claims certain inherent advantages. First, at $300^{\circ} \mathrm{C}$ it is a low-temperature process especially useful for creating interlevel dielectrics in doublemetalization devices. Second, at 3,000 Angstrom per minute, it is significantly faster than conventional depositon.

Additionally, the laser technique allows greater control over the chemical products. Varying the wavelength used in silicon nitride deposition, for example, achieves control over how much hydrogen becomes bonded to the silicon and how much to the nitrogen.

Such capabilities are important in fine-tuning the charge-trapping and charge-retention properties of silicon nitride when used as a gate material is erasable programmable read-only memories. Yet another advantage is the absence of risk from radiation damage, a problem at times with plasma deposition.

Collins's success is already raising some eyebrows. Osgood says, "A lowtemperature process with greater bond-breaking specificity - after one year, that's darn good." Another observer, Ted Kamins, project leader in the semiconductor devices labs for Hewlett-Packard Co. in Palo Alto, Calif., says that laser deposition "looks very intriguing. It certainly sounds like an attractive alternative to plasma processing since it would avoid radiation damage. It needs a lot more investigation but it looks very promising at this time for any IC application and particularly where you need a lowtemperature dielectric."

\section{BRIEFS}

CRYOGENIC MATERIALS are the subject of a conference to be held Aug. 15-19 in conjunction with the Cryogenic Engineering Conference. Topical areas will include electrical, magnetic, thermal and other applied physical properties of metals, semiconductors and insulators including effects of radiation, stress, etc. The emphasis will be on work related to understanding and characterizing material behavior for low temperature applications.

The conference will be held in Colorado Springs, Colo. For more information contact the program co-hairman, K.T. Hartwig Jr., University

Wisconsin-Madison, 911 Engineering Research Building, Madison, Wis. 53706, phone (608) 263-5028, or the conference administrator, Centennial
Conferences, 1215 Mapleton Avenue, Boulder, Colo. 80302.

\section{THE AMERICAN NUCLEAR} SOCIETY says a recent survey found that nine of every 10 scientists favor nuclear power generation. In its "Nuclear Report" to its members, it says the public is seriously misinformed on this point, mistakenly believing that a quarter of all scientists oppose further development of nuclear power.

"The press, its biases, and its preferred 'experts' are exposed by [Stanley] Rothman and [S. Robert] Lichtner [who did the survey], who say the scientific community does not address the public," the newsletter asserts. Rather, the relatively small percentage of anti-nuclear scientists, and even non-scientists such as Ralph
Nader, monopolize the press's reporting on the issue.

THE JOURNAL OF MATERIALS EDUCATION is the new name of the former Journal of Education Modules for Materials Science and Engineering. The change was effective at the beginning of this year.

The journal-textbook hybrid will continue to provide copyright-free instructional modules, but will broaden its scope to include meeting announcements, book reviews, pedagogical papers, etc. For information write to the Managing Editor, Journal of Materials Education, 110 Materials Research Laboratory, Pennsylvania State University, University Park, Pa. 16802. 